\title{
Examining Customers' Continuance Intentions towards E-wallet Usage: The Emergence of Mobile Payment Acceptance in Vietnam
}

\author{
Nguyen Ngoc Duy PHUONG ${ }^{1}$, Ly Thien LUAN ${ }^{2}$, Vu Van DONG ${ }^{3}$, Nguyen Le Nhat KHANH ${ }^{4}$
}

Received: July 03, 2020 Revised: July 19, 2020 Accepted: August 10, 2020

\begin{abstract}
The purpose of the research is to identify antecedents of mobile wallet continuance intention in Vietnam. A self-administered questionnaire was distributed to collect data from a total of 276 respondents. Partial least squares structural equation modeling was employed for analyzing the data. Five mobile wallet features - mobile application quality, mobile wallet familiarity, situational normality, payment security, and feedback mechanism - are introduced as fundamental elements, which influence customer' continuance intention to use mobile wallet in Vietnam. The results indicate that mobile quality application and familiarity can significantly influence perceived ease-of-use (PEOU) and perceived usefulness (PU), but situational normality has an impact only on PEOU. PEOU and PU are positively related to satisfaction. On the other hand, payment security and feedback mechanism affect positively customer' trust. As a result, the positive effects that satisfaction and trust have on electronic wallet continuance intention are confirmed. The findings can be used to advise mobile wallet providers to improve their platform design and services to retain users. As a theoretical contribution, this study combines the Technology Acceptance Model, Unified Theory of Acceptance and Use of Technology to investigate the key determinants on continuance intention in the context of electronic wallet in Vietnam.
\end{abstract}

Keywords: TAM, Continuance Intention, Mobile Wallet, PLS-SEM, Vietnam

JEL Classification Code: M13, M15, M30

\section{Introduction}

Electronic wallets are the digital form of a physical wallet. The users are familiar with making a cash payment when they want to buy a product or service. However, if they want to make online or offline payments by using a mobile wallet application on a mobile device such as mobile phone, smartphone, etc., they could make a deposit of the certain amount into their mobile wallet through a debit card or

${ }^{1}$ First Author and Corresponding Author. School of Business, International University Ho Chi Minh City, Vietnam [Postal Address: Quarter 6, Linh Trung Ward, Thu Duc District, Ho Chi Minh City, 700000, Vietnam] Email: nndphuong@hcmiu.edu.vn

${ }^{2}$ School of Business, International University Ho Chi Minh City, Vietnam. Email: thienluan221096@gmail.com

${ }^{3}$ Vice President, Baria Vungtau University, Vietnam.

Email: dongvv@bvu.edu.vn

${ }^{4}$ Quan Thu Duc Hospital,Vietnam. Email: nhatkhanh@bvtd.vn

(c) Copyright: The Author(s)

This is an Open Access article distributed under the terms of the Creative Commons Attribution Non-Commercial License (https://creativecommons.org/licenses/by-nc/4.0/) which permits unrestricted non-commercial use, distribution, and reproduction in any medium, provided the original work is properly cited. internet banking and, then, perform transactions for goods and services. Customers could use the new cashless payment method to pay utility bills, transferring money, and making payment for financial transactions. Electronic wallet is one of the most convenient online payment systems that can be used to make numerous payments at any time of day or anywhere in the world. Customers could use mobile wallets to conduct transactions in multi-channels like consumer-toconsumer, consumer-to-business, consumer-to-machine and consumer-to-online (Shin, 2009; Lee, 2019). The mobile wallet model is similar to the concept of mobile banking and Internet banking. Mobile banking is a mobile application, which allows banking customers manage their bank account by using a smartphone. The transactions include deposits, withdrawals, transfers, bill payments, and balance inquiries. An electronic wallet could be considered to be a personal folder that includes customer information required from service providers for ensuring security of mobile transactions (Chawla, 2019). The majority of poor residents in emerging countries does not have a bank account, but has a smartphone, so mobile payment providers supply the system to support them in paying utilize bills (Cox, 2013). 
Mobile payment is becoming popular in Vietnam due to the presence of many E-wallets such as Momo, Zalopay, Viettelpay, Moca. Electronic wallet can be viewed as a modern financial transaction model, in which the money could be kept intangibly, and transactions could be conducted successfully via a smartphone without the worry of losing sensitive information. As Vietnam's economy has been growing fast and strongly recently, the demand for services is rising significantly, especially in the finance industry. Also, with the trend of 'cashless' society among Vietnamese residents, more and more E-wallets have cooperated with retail stores to broaden their payment network. Moreover, they have invested billions of VND in promotion campaigns to attract more users. Many customers use E-wallets to pay utility bill due to their convenient and promotion from new users to existing users. Furthermore, E-wallets have been used as free money transfer gateways between two customers belonging to different banks. According to State Bank in Vietnam, in 2019, there are around 20 E-wallets in the market. This upward growth has interested, not only foreign investors (SamSung, Goldman Sachs), but also domestic investors (Vingroup, Viettel, VNPay). The total number of E-wallet users is approximately 10 million, however, it could increase dramatically since there are more than 100 million mobile phone users in Vietnam. However, because of the huge market potential, the competition in mobile payment market has heated up with the participation of many new organizations, and users could choose to use other payment system options due to attractive special offers provided to new customers. Thus, customer loyalty plays a key role in the development of E-wallet payment systems for expanding their market share.

\section{Literature Review}

Technology acceptance model is one of the most famous conceptual theories in the digital platform system research field. Originally, it is proposed for employees' technology acceptance in organizations. There are two fundamental determinants in the model, namely, perceived ease-of-use (PEOU) and perceived usefulness (PU), which verify the intention of users to agree or disagree with an information technology system. PU relates to the rate at which users recognize usage of a certain digital platform to be suitable to them, while PEOU is regarded as the degree in which users identify usage of the IT system would be easy to learn (Davis, 1989). But, the key concern about the theory background is that the model is insufficient to demonstrate customers' continuance behaviors. For developing the model, the researchers should figure out factors influencing PU and PEOU (Benbasat, 2007). Hence, investigating which E-wallet features could be considered to be essential factors of TAM are significant. Moreover, the author will integrate
TAM model into relevant conceptual theories that would present a more holistic theory background in demonstrating customer' continuance intention of digital platform, specifically in an E- wallet system (Lee et al., 2016; Zhou, 2018). Finally, this research will use TAM model as one of the main theories to build the conceptual model explaining customer continuance intention of E-wallet platform.

The Unified Theory of Acceptance and Use of Technology (UTAUT) model was developed to improve TAM model, which sought to investigate customer intentions to use an information system and their continuance behavior (Venkatesh, 2003). Four core components - performance expectancy, effort expectancy, social influence, and facilitating condition - are regarded as essential antecedent variables of behavioral intention and ultimately user behavior. Performance expectancy refers to the expectation of customers about the system effectiveness that using the E-wallet system would promote their behavioral practice of making payment by managing their time, money and effort efficiently, also providing them beneficial payment system without paying any fee for transactions and fast responsive customer support system. The second variable is effort expectancy, mainly defined as the expectation of customers about the system simplification that using E-wallet system is easy to learn for them (Abdinoor, 2017; Arora, 2018). The third variable is social influence, which shows that customers' social effects have a considerable impact on their judgements and attitudes when they decide to do something such as giving advice to friends, relatives and supervisors. The last variable is facilitating conditions, which can be seen as the extent to which a customer believes that the right organizational and technical structure is available to gain their acceptance of the E-wallet system.

UTAUT is a development of technology acceptance model, also its effectiveness in illustrating digital platform system acceptance are shown by other previous investigations. The forecasting capability of UTAUT has been confirmed through various information technology platforms adoption, such as online banking (Martins, 2014; Le et al., 2019); library self-service (Wu, 2018); tablet device (Magsamen, 2015); and mobile wallet (Chawla, 2019). However, based on past research, the author could add some new factors to enhance its explanatory power based on specific context. Some authors suggested that payment security and customer trust have considerable impact on customer continuance intention to use the E-wallet payment system (perceived credibility) that should be included to the research model because they are principal reasons for low adoption of E-wallet payment service. As a result, in this research, the author integrates payment security, feedback mechanism, and trust with E-finance continuance intention model (Zhou, 2018) to investigate the customer continuance intention in E-wallet context in Vietnam. 
E-wallet payment system also is progressing rapidly in developing country like China. Zhou (2014) conducted a research to investigate the determinants affecting customer continuance usage toward mobile payment in China. The researcher collected valid data by using a survey questionnaire and he applied structural equation modeling (SEM) method. Performance expectancy, trust in mobile payment, and flow factors are found to have impacted customer continuance usage. The flow factor accounted for the largest impact. Additionally, performance expectancy and flow are affected significantly by system quality. Yu (2018) suggested that customer trust in E-wallet payment system could be affected by customer trust in online payment system and two sourcetarget relationship determinants such as perceived similarity and entitativity.

Moreover, customer satisfaction and customer continuance intention to use E-wallet payment system in an online-E-wallet payment context are affected considerably by the customer trust. The author used data collected from 219 E-wallet payment system customers in China to test the proposed model empirically. The result demonstrated that the trust transfer process influences positively the customers' continuance intention to use E-wallet payment system through their satisfaction. Customer satisfaction also is found to be a key element affecting customer continuance intention. Furthermore, trust in online payment system, perceived similarity and perceived entitativity between online and E-wallet payment systems affect positively customer trust in E-wallet payment system. Additionally, Zhou (2018) examined the factors affecting customer continuance intention in E-finance context. He used an online survey to collect data and employed partial least squares structural equation modeling to analyze the data. The results demonstrated that E-wallet features such as website quality, familiarity and situational normality play a major role in perceived ease-ofuse (PEOU) and perceived usefulness (PU) of customers. PEOU and PU, incorporated with brand reputation, have positive influence on confirmation, which further affects satisfaction. Customer satisfaction and customer trust have a positive effect on E-wallet customer continuance intention, besides that the customer trust is proven to be a considerable mediator in the relationship between customer satisfaction and customer continuance intention.

In India, E-wallet platforms are becoming popular due to payment convenience. Hence, Kumar (2018) decided to investigate the effect of perceived usefulness, payment security, perceive ease-of-use, trust, grievance redressal, and satisfaction on inexperienced customers' continuance intention to E-wallet usage. He developed a conceptual model from the expectation-confirmation theory and applied structural equation modeling to test it empirically by using data from E-wallets young customers in India. The results revealed that perceived usefulness and perceived ease-of-use influence considerably customer satisfaction and customer continuance intention to use E-wallets. Customer satisfaction also is affected strongly by payment security, and grievance redressal moderates the influence of payment security on continuance intention to use E-wallets. In addition, the mechanism of developing customer belief during the development from online payment system to E-wallet payment system was investigated, also the influence of trust on customer satisfaction and customer continuance intention to use E-wallet payment system were examined. From the trust transfer theory background, Chawla (2019) investigated the factors that affect customer's attitude and intention to use E-wallets in Indian. He suggested a multidisciplinary model based on the TAM model and UTAUT model, also on related studies of variables, which have effect on E-wallet payment system adoption. A nationwide essential questionnaire was sent to Indian residents. In total, 744 respondents were collected and 17 hypotheses were proposed. The author applied PLS-SEM method to predict and test the hypothesized model. As the result, PEOU, PU, trust, security, facilitating conditions and lifestyle compatibility affect greatly the customer attitude and intention to use E-wallets. PU and trust were influenced significantly by PEOU. In addition, PU had significant impact on customer trust, customer attitude and intention. Moreover, payment security and PU were key effects on determining trust.

To provide better understanding about customer continuance intention, the author also reviewed several papers related to other information technology systems. In the banking industry, Susanto (2016) examined the factors of customer continuance intention to use smartphone banking services at the post-consumption phase. A theoretical model was proposed, the expectation-confirmation model (ECM). As per the results, customers' confirmation after the initial use of smartphone banking services affects significantly payment security, perceived usefulness, trust, and customer satisfaction. Payment security plays a key role in customer trust, while perceived usefulness accounted for considerable influence on customer trust, customer satisfaction and customer continuance intention. In addition, customer satisfaction and self-efficacy strongly affect customer continuance intention. Customer trust was found to have an important influence on customer satisfaction.

Ofori (2017) investigated the determinants influencing customer continuance intention to use internet banking system based on the institutional trust theory. A questionnaire was used to collect data from 481 internet banking users of a bank in Ghana, and the PLS-SEM method was applied to analyze the data. The results showed that information quality, service quality, privacy and security concerns are key factors in customer trust and customer satisfaction. Besides that, structural assurance and situational normality 
have considerable impact on customer trust. The influences of customer satisfaction and customer trust on customer continuance intention are confirmed. On the other hand, in the mobile shopping industry, Shang (2017) examined the underlying variable affecting customer continuance intention of food and non-food products through smartphones and other mobile devices. He combined the TAM and ECM models to propose a new model focusing on perceived value (PV). The data collected from 203 Chinese mobile shoppers (m-shoppers) were analyzed using structural equation modeling with the partial least square method. The results demonstrated that value for money played the key role in customer satisfaction and customer continuance intention in online food mobile shopping context, but perceived usefulness only influenced non-food shopper's continuance intention.

Shao (2019) investigated the impacts of legally-binding and market-driven institutional mechanisms on increasing customers' trust and customer continuance intention in the ridesharing mobile application and also verified whether the customer' trust in the drivers could carry customers' trust over to ridesharing mobile application. He used an online survey to collect data from customers of DiDi ridesharing mobile application in China. SEM method was applied to analyze the conceptual model and research hypotheses. The results indicated that market-driven institutional mechanisms, consisting of feedback and surge pricing influence significantly customers' trust in the ridesharing platform. Moreover, legally-binding institutional mechanisms factors, namely, payment security and driver certification, have a considerable impact on customers' trust. Furthermore, customers' trust in the platform is converted completely to customer trust in the drivers.

\subsection{Impact of Mobile Application Quality on Customer's PEOU and PU}

Many platform systems have been established to serve the customer's need and, their quality contribute greatly to the customer satisfaction. Smartphone is becoming essential to residents' life, so the good quality mobile application will raise customer satisfaction of E-wallet usage and will encourage them to continue using E-wallet payment system whenever they need making a bill payment. Similarly, a good quality E-banking system will strengthen customer satisfaction (Kim, 2009) and continuance intention to use online banking payment system (Yeh, 2009). In the E-finance context, the mobile application quality has a considerable impact on customer's experience through PEOU and PU of the users (Fathema, 2015; Ofori, 2017; Zhou, 2018). Hence, the authors suggest that the quality of the mobile application E-wallet payment system affects positively the PEOU and PU of users:
Hypothesis 1a: Mobile application quality influences positively the customer's PEOU of an E-wallet payment system.

Hypothesis 1b: Mobile application quality influences positively the customer's PU of an E-wallet payment system.

\subsection{Impact of E-wallet Familiarity on Customer's PEOU and PU}

In the E-wallet context, familiarity relates to the degree to which a customer gets acquainted with payment method including making a payment or the popularity of the payment system in daily life. Familiarity comes from previous experience with the system, removes its usage difficulties, and supports users who want to be familiar with E-wallet payment system (Zhou, 2018). Hence, promoting customer's familiarity leads to the increase of customer's PEOU and PU. Therefore, we suppose that E-wallet familiarity has positive impact on the customer's PEOU and PU:

Hypothesis 2a: Familiarity influences positively the customer's PEOU of an E-wallet platform.

Hypothesis 2b: Familiarity influences positively the customer's $P U$ of an E-wallet platform.

\subsection{Impact of Situational Normality on Customer's PEOU and PU}

In the digital era, customer trust in a platform is dependent on our earlier understandings about some related systems (Chen, 2010; Koo, 2011). Situational normality of payment system takes an important role in customer trust; customers will use your services if they believe in your system (Ofori, 2017). However, customers could reject to use your platform if your system is different to other systems, which they have used before (Gefen, 2003). Situational normality affects significantly customer's PEOU and PU in E-wallet context (Zhou, 2018). Therefore, the authors suggest the following:

Hypothesis 3a: Situational normality influences positively the customer's PEOU of an E-wallet platform.

Hypothesis 3b: Situational normality influences positively the customer's $P U$ of an E-wallet platform.

\subsection{Impact of Customer's PEOU and PU on Customer's Satisfaction}

Customer's perceived usefulness is determined to affect positively customer behaviors to work with an information system (Venkatesh, 2000; Venkatesh, 2008). Recently, customer's perceived usefulness and perceived ease-of-use influence considerable customer satisfaction in using life insurance mobile application service (Lee, 2015). In the 
e-government service, customer's perceived ease-of-use and perceived usefulness have positive effect on customer satisfaction when using government website (Sachan, 2018). Moreover, perceived usefulness and perceived ease-of-use affect significantly customer satisfaction of the mobile e-commerce context (Shao, 2019). Hence, the positive connection amongst customer's PEOU, PU and customer satisfaction in the E-wallet payment system context needs to be examined in this research. The authors propose the following hypotheses:

Hypothesis 4a: Customer's PEOU influences positively customer satisfaction of an E-finance platform.

Hypothesis 4b: Customer's PU influences positively customer satisfaction of an E-finance platform.

\subsection{Impact of Feedback Mechanism and Payment Security on Customer Trust in the E-Wallet Platform}

Feedback was regarded as an important feature in a lot of digital platforms, which is an effective way to support customers for checking the accuracy of information provided by service providers. Also, it could be seen as an instant channel of communication between customers and service providers whenever the customers have problems with system usage. In the past decades, customers have been familiar with feedback mechanisms in some famous e-commerce platforms such as eBay, Amazon and Alibaba. In addition, customers trust other customers' verbal feedbacks about service providers (Doney, 1997). Customer trust is proven to be affected significantly by feedback mechanism in the group of dealers on popular social media channels (Pavlou, 2004). In the E-wallet payment system, feedback is a convenience feature to build up customers' trust by protecting their rights and interests (Shao, 2019). Hence, the rise of positive customer feedbacks will promote the increasing of customer trust.

Payment security is regarded as a key function, which could support banking system to gain customer trust (Kim, 2008; Susanto, 2016). In the digital era, because a hacker could break into a server system of financial institutions to steal customers' money and their private information, most online payment systems have applied identity authentication and encryption mechanisms to check whether the money transactions were conducted by the real customers or not. It would engender customer' confidence in making payment online. When customers pay utility bills or buy mobile phone cards, cinema tickets or transfer money to relatives, they could make the payment on E-wallet platform by using their smartphone, and the money is sent instantly to the service provider' account through E-wallet payment system. The online transaction process could raise customers' perceived risk in losing private information. Hence, payment security feature has an important impact on customer trust in the e-wallet payment system (Yang, 2016; Chawla, 2019; Shao, 2019). The authors suppose that:

Hypothesis 5a: Feedback mechanism influences positively customer trust in an E-wallet platform.

Hypothesis 5b: Payment security influences positively customer trust tin an E-wallet platform.

\subsection{Impact of Customer Satisfaction on Customer Continuance Intention}

Satisfied customers tend to continue using their current online payment system and recommend other people to use it. Satisfaction could be seen as the customers' perception of how effective the system supports them to handle previous monetary transactions that relates to the ability to deal with similar future payments. (Halilovic, 2011; Zhang, 2015; Ofori, 2017 \& Zhou, 2018). We hypothesize that, if the customers are satisfied with E-wallet services, they definitely continue using it next time they need making any payments:

Hypothesis 6: Customer satisfaction influences positively customer continuance intention of an E-wallet platform.

\subsection{Impact of Customer Trust on Customer Continuance Intention}

Customer trust is becoming an essential factor that needs to be considered in mobile commerce (Hong, 2013; Shaw, 2014). Moreover, customers will have an intention to purchase products if they trust the reputation of the merchant (Han, 2011; Hajli, 2014). The positive impact of customer trust on customer continuance intention in E-wallet context was confirmed (Zhou, 2011; Kumar, 2018; Chawla, 2019). If the E-wallet payment system gains more customer trust, they will accept to work with the digital system whenever making daily payment (Zhou, 2018). The authors hypothesized that:

Hypothesis 7: Customer trust influences positively customer continuance intention of an E-wallet platform.

E-wallet system can be viewed as a combination of digital platform, mobile application and financial services. The author proposes a research model that applied TAM, UTAUT and TAM2 theory models. Five features of E-wallet system such as mobile application quality, familiarity, situational normality, payment security, and feedback mechanism, will be examined with the influence of customer trust. Mobile application quality, familiarity and situational normality were pointed out as having an impact on PEOU and PU in E-finance platform. Then, PEOU, PU are hypothesized to be antecedents of user satisfaction (Zhou, 2018). 


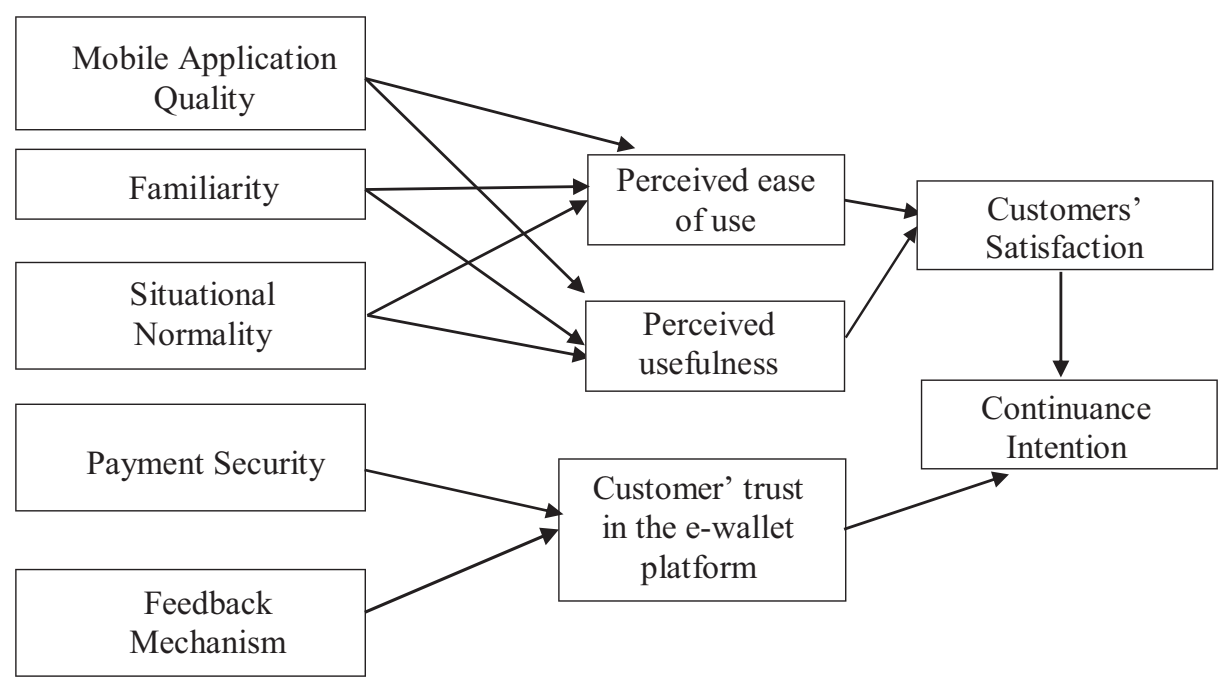

Figure 1: Research Model

On the other hand, payment security and feedback mechanism influence customer trust in the E-wallet platform (Chawla, 2019; Shao, 2019). Lastly, the positive impact of customer trust and customer satisfaction on customer continuance intention of an E-wallet platform needs to be investigated (see Figure 1).

\section{Research Methods and Materials}

\subsection{Research Design}

Quantitative methods are being used in this research to test theory and attempt to generalize from the findings toward a conclusion. A conceptual model (Figure 1) has been proposed based on the detailed literature review. To study the relationship between variables, quantitative method is used to portray the relationship numerically and mathematically through analysis. To test the model in the most realistic way possible, the study was conducted based on an online survey surveys because it allows the researcher to approach a large number of participants and collect data for numerous questions in limited time (Nguyen \& Nguyen, 2018). To collect the data, an online survey (a selfadministered questionnaire) is sent to a broad diversity of citizens in Ho Chi Minh City and published on several social networks. Choosing Ho Chi Minh City helps the researcher to reduce time and cost as well as improve the efficiency of questionnaire administration. The online Google form was transferred to more than 300 Ho Chi Minh City citizens, conducted from April to May, 2020. Then, 276 responses were received, all of them were deemed valid. As per the result, 253 respondents have used mobile wallet application, and 23 respondents have not. The participants, from the residential community, including university students, staff and office workers, were recruited by invitation through social networks. Partial least squares structural equation modeling (PLS-SEM) method is applied to test the proposed model. The method is used by researchers in several fields such as mobile wallet (Yu, 2018; Zhou, 2018 \& Chawla, 2019), internet banking (Ofori, 2017; Salem, 2019), mobile shopping (Shang, 2017) and ridesharing (Shao, 2019).

\section{Results and Discussion}

The profile of the mobile wallet customers represented in the research spread over every analytics. Overall, 55\% of the participants are male and $45 \%$ female. The biggest age bracket of respondents is $18-35(87.35 \%)$. This represents the young generation most likely to use the E-wallet payment system. Regarding the educational level, $85.4 \%$ have/are studying a bachelor's degree. The findings also reveal that the respondents' monthly salary is VND20 million and above (35.6\%), between VND3 million and 7 million $(21.34 \%)$, and below VND3 million (15.02\%).

\subsection{Assessment Measurement Model}

Outer loadings of the model are calculated first. Every single loading of indicators in the research was inspected to check whether the constructs satisfy the criteria requirements. Particularly, all the factor loadings are recommended to be at least 0.7 . After analyzing data, all findings are larger than the required value 0.7 . The outer loadings of the factors fall in the range of 0.719 to 0.941 , which are exhibited in detail in Table 1. The internal consistency is examined using Cronbach's Alpha. The results show (see Table 1) that 
the values of all the factors are larger than the minimum required value of 0.7 (Zhou, 2018). Moreover, for checking convergent validity of the measurement model, Ofori (2017) suggested that the average variance extracted (AVE) for each latent construct should be greater than 0.5. As illustrated in Table 1, the values of Cronbach's Alpha ranged from 0.710 to 0.927 and the values of composite reliability ranged from 0.837 to 0.954 , therefore confirming the high reliability of the data. On the other hand, AVE values for all factors are examined to be higher than the 0.5 threshold, ranging from 0.632 to 0.873 . Hence, good convergent validity is illustrated by the measurement model.

Another crucial criterion that needed to be measured is discriminant validity, which interprets the degree of difference of every variable in the model. Fornell-Larker criterion is used to check the AVE of each latent construct, which should be larger than the highest squared correlations between any other construct (Fornell, 1981). The square root of the AVEs for each construct is greater than the cross correlation with other constructs. Hence, good discriminant validity is shown by the measurement model (see Table 2).

\subsection{Assessment Structural Model}

After evaluating the reliability and validity of variables in the measurement model, the structural model is applied to test the hypotheses (Ofori, 2017; Zhou, 2018). In this section, typical calculations performed including collinearity assessment, coefficient of determination, effect size and direct effect. Particularly, variance inflation factor is employed to detect collinearity problems, while coefficient of determination is applied to estimate the predictive precision using R square. Additionally, F square is used to measure the influence of predictor constructs on dependent construct. To indicate the direct effect of predictors on the dependent variable in the path model, path coefficients were needed.

Table 1: Reliability and Validity Measures

\begin{tabular}{|l|c|c|c|c|c|}
\hline Constructs & Items & Factor Loadings & Cronbach's Alpha & Composite Reliability & AVE \\
\hline Continuance Intention (CI) & 5 & $0.800-0.852$ & 0.881 & 0.913 & 0.677 \\
\hline Familiarity (FAM) & 3 & $0.906-0.915$ & 0.710 & 0.837 & 0.632 \\
\hline Feedback Mechanism (FM) & 3 & $0.767-0.822$ & 0.898 & 0.936 & 0.830 \\
\hline Mobile Application Quality (MQ) & 4 & $0.719-0.882$ & 0.813 & 0.878 & 0.645 \\
\hline Perceived Ease of Use (PEOU) & 5 & $0.837-0.892$ & 0.918 & 0.939 & 0.754 \\
\hline Payment Security (PS) & 5 & $0.727-0.912$ & 0.905 & 0.930 & 0.729 \\
\hline Perceive Usefulness (PU) & 5 & $0.787-0.920$ & 0.915 & 0.937 & 0.748 \\
\hline Customer Satisfaction (SA) & 3 & $0.924-0.941$ & 0.927 & 0.954 & 0.873 \\
\hline Situational Normality (SN) & 3 & $0.812-0.920$ & 0.849 & 0.909 & 0.769 \\
\hline User's Trust (UT) & 5 & $0.791-0.915$ & 0.909 & 0.933 & 0.735 \\
\hline
\end{tabular}

Table 2: HTTM scores for discriminant validity

\begin{tabular}{|l|c|c|c|c|c|c|c|c|c|c|}
\hline Item & CI & FAM & FM & MQ & PEOU & PS & PU & SA & SN & UT \\
\hline CI & 0.823 & & & & & & & & & \\
\hline FAM & 0.640 & 0.795 & & & & & & & & \\
\hline FM & 0.669 & 0.516 & 0.911 & & & & & & & \\
\hline MQ & 0.721 & 0.541 & 0.573 & 0.803 & & & & & & \\
\hline PEOU & 0.697 & 0.509 & 0.498 & 0.752 & 0.869 & & & & & \\
\hline PS & 0.631 & 0.450 & 0.716 & 0.539 & 0.472 & 0.854 & & & & \\
\hline PU & 0.732 & 0.535 & 0.526 & 0.684 & 0.771 & 0.473 & 0.865 & & & \\
\hline SA & 0.734 & 0.606 & 0.633 & 0.710 & 0.659 & 0.559 & 0.712 & 0.934 & & \\
\hline SN & 0.433 & 0.374 & 0.372 & 0.528 & 0.495 & 0.461 & 0.468 & 0.436 & 0.877 & \\
\hline UT & 0.665 & 0.503 & 0.694 & 0.560 & 0.490 & 0.727 & 0.490 & 0.672 & 0.405 & 0.858 \\
\hline
\end{tabular}

Note: Diagonals (in bold) represent square root of the AVE 
Collinearity should be evaluated before testing the relationships between constructs since path coefficient is evaluated basing on the regression of dependent variables and their predictors (Ofori, 2017). Specifically, if the levels of collinearity significantly rise among the predictors, the measurement of path coefficients would be bias. We investigate the VIF values between the constructs to identify the level of collinearity. Collinearity happens when the VIF value are greater than 5.00. In this research, all the VIF values of the latent variables are smaller than 5 , indicating that there was no collinearity issue.

Another criterion to be calculated in the structural model is coefficient of determination. It is applied to express the extent the dependent variable is explained by its predictors. The measurement is based on $\mathrm{R}$ square values, which range from 0 to 1 . The $R$ square value of $0.25,0.5$ and 0.75 are proposed to be weak, moderate and substantial (Hair, 2014). From the data showing in table 5, it is clearly seen that the $\mathrm{R}$ square values were moderate for $\mathrm{CI}(\mathrm{R}$ square $=0.592), \mathrm{PEOU}(\mathrm{R}$ square $=0.591), \mathrm{PU}$ $(\mathrm{R}$ square $=0.517)$, customer's satisfaction $(\mathrm{R}$ square $=$ 0.537 ) and customer's trust $(\mathrm{R}$ square $=0.590)$. The findings illustrate that mobile application quality, familiarity and situational normality took account for $59.1 \%$ of all variance in PEOU and $51.7 \%$ of variance in PU. On the other hand, payment security and feedback mechanism together described $59 \%$ of variance in customer's trust. Moreover, $53.7 \%$ of the variance in customer' satisfaction was demonstrated, also $59.2 \%$ of variance in customer continuance intention was illustrated. The results of $\mathrm{R}$ square show that the structural model approved the level of predictive accuracy.
Effect size, or f square, can assist the evaluation of the influence level of a particular predictor on the dependent variable (Zhou, 2018). F square values equal $0.02,0.15$ and 0.35 indicating the small, moderate and large impact of a particular independent variable on dependent one, respectively (Hair, 2014). Results from the study show that it is a small effect to perceived ease-of-use ( $\mathrm{f}$ square $=0.029$ ) and perceived usefulness (f square $=0.068$ ) if familiarity is omitted. Moreover, the relationship of perceived easeof-use to customer' satisfaction, situational normality to perceived ease-of-use, situational normality to perceived usefulness and customer's trust to continuance intention are determined to have small effect sizes (f square $=0.065$, $0.025,0.022$ and 0.132 ). In addition, the relationships between feedback mechanism and user's trust, mobile application quality and perceived usefulness, payment security and customer's trust, and perceived usefulness and customer's satisfaction have effect sizes of 0.152 , $0.305,0.263$ and 0.221 correspondingly, implying that the predictors of the relationships have medium effects in producing the R square for their endogenous constructs. On the other hand, the removal of mobile application quality influences considerably perceived ease-of-use with f square reaching 0.546. Besides, customer's satisfaction has large effect in producing the $\mathrm{R}$ square for customer intention (f square $=0.368$ ).

The coefficient significance is tested by PLS-SEM relying on nonparametric bootstrapping (Hair, 2014). In this study, there are 253 cases and 5,000 subsamples. After running bootstrapping procedure, $\mathrm{t}$-values were evaluated so as to examine the statistical significance of coefficient (see Table 3).

Table 3: Model's Path Coefficient

\begin{tabular}{|c|c|c|c|c|c|}
\hline Hypothesis & Relationship & Path coefficient & $\mathrm{T}$ - Statistics & Sig. level (p) & Results \\
\hline $\mathrm{H} 1 \mathrm{a}$ & $M Q$-> PEOU & 0.619 & 11.224 & 0.000 & Supported \\
\hline $\mathrm{H} 1 \mathrm{~b}$ & $M Q->P U$ & 0.503 & 8.003 & 0.000 & Supported \\
\hline $\mathrm{H} 2 \mathrm{a}$ & FAM -> PEOU & 0.13 & 2.523 & 0.014 & Supported \\
\hline $\mathrm{H} 2 \mathrm{~b}$ & FAM -> PU & 0.217 & 4.122 & 0.000 & Supported \\
\hline $\mathrm{H} 3 \mathrm{a}$ & SN -> PEOU & 0.12 & 2.108 & 0.037 & Supported \\
\hline $\mathrm{H} 3 \mathrm{~b}$ & SN -> PU & 0.121 & 1.878 & 0.064 & Rejected \\
\hline $\mathrm{H} 4 \mathrm{a}$ & PEOU -> SA & 0.272 & 3.339 & 0.001 & Supported \\
\hline $\mathrm{H} 4 \mathrm{~b}$ & $\mathrm{PU} \rightarrow \mathrm{SA}$ & 0.502 & 6.574 & 0.000 & Supported \\
\hline $\mathrm{H} 5 \mathrm{a}$ & FM -> UT & 0.357 & 4.033 & 0.000 & Supported \\
\hline $\mathrm{H} 5 \mathrm{~b}$ & PS -> UT & 0.471 & 6.402 & 0.000 & Supported \\
\hline $\mathrm{H} 6$ & $\mathrm{SA} \rightarrow \mathrm{Cl}$ & 0.523 & 8.343 & 0.000 & Supported \\
\hline $\mathrm{H} 7$ & UT $\rightarrow \mathrm{Cl}$ & 0.313 & 4.876 & 0.000 & Supported \\
\hline
\end{tabular}




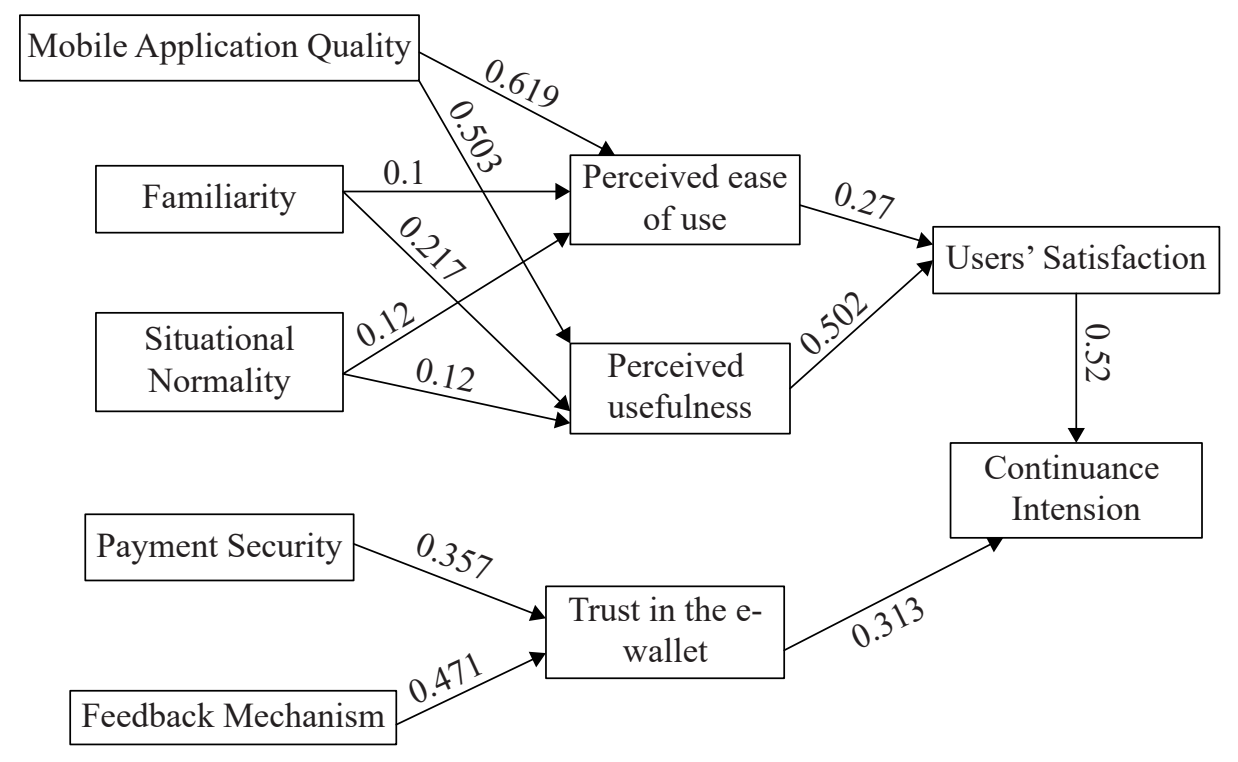

Figure 2: Path structural relationship

Table 3 describes the path coefficients and hypotheses testing of the research. Among 12 proposed hypotheses, all were supported, except one. The finding shows that the two mobile wallet features, namely, mobile application quality and familiarity are verified to have positive and significant impact on the perceived ease-of-use and perceived usefulness. However, situational normality has only effect on perceived ease-of-use. As a result, $\mathrm{H} 1 \mathrm{a}, \mathrm{H} 1 \mathrm{~b}, \mathrm{H} 2 \mathrm{a}, \mathrm{H} 2 \mathrm{~b}$ and $\mathrm{H} 3 \mathrm{a}$ are supported, while $\mathrm{H} 3 \mathrm{~b}$ is rejected. The result has indicated that the influence of perceived ease-of-use and perceived usefulness on users' satisfaction are significant. Moreover, payment security and feedback mechanism have considerable impacts on customer' trust. Finally, customer' continuance intention in using mobile wallet. Therefore, H4a, H4b, H5a, H5b, H6 and H7 are supported (see Figure 2).

\section{Discussion and Managerial Implications}

The results display the considerable effect of perceived ease-of-use on customer's satisfaction. In fact, some studies have confirmed the effect of the factor on the customer's satisfaction when using E-wallet in different countries (Kumar, 2018; Zhou, 2018 \& Chawla, 2019). In the context of Vietnam, perceived ease-of-use influences strongly customer's satisfaction in HCMC. Users learn to operate E-wallet easily (mean $=4.174)$. Also, becoming skillful at doing money transactions from E-wallet is easy for them (mean $=4.142)$. Moreover, payments done though E-wallet require minimum effort $($ mean $=4.051)$. Transferring money by E-wallet system is easy since it does not require many steps $($ mean $=4.055)$.

Overall, users find E-wallet easy to use (mean = 4.174). Perceived usefulness was considered to illustrate its great impact on E-wallet customers' satisfaction in HCMC. The research also confirms the results of many studies that customers' perceived usefulness significantly influences their satisfaction toward using E-wallet (Kumar, 2018; Zhou, 2018 \& Chawla, 2019). Using E-wallet payment system could support customers to make payments faster than other payment options (mean $=4.15)$. They also believe E-wallet is useful for conducting online transactions (mean $=4.162$ ). Moreover, they realize that using E-wallet could maximize their effectiveness of taking online payments (mean = 4.146). Customers admit that it is easier for them when they use E-wallet to make online payments (mean $=4.15)$. E-wallet also improves the quality of online transaction to them $($ mean $=4.04)$.

One of the factors that peek the interest of many is mobile application quality. The result indicates that mobile application quality is a crucial determinant of perceived ease-of-use and perceived usefulness, a good quality mobile application will support customers finding the information system useful and beneficial (Zhou, 2018). Therefore, in the Vietnamese market, mobile application quality has a large impact on the satisfaction of HCMC residents to use E-wallet mobile application. Familiarity was identified to have a substantial impact on perceived ease-of-use and perceived usefulness of E-wallet users. 
The result strongly supports previous findings by Zhou (2018) who pointed out that familiarity played an efficient role in creating a tendency among users to continue using the E-wallet next time when they need doing a money transaction/payment. The findings indicated that E-wallet's brand name becomes popular to customers by advertising campaigns on online social media channels such as Facebook, Youtube and Google (mean = 3.553). The research results contradict several findings by Ofori (2017) and Zhou (2018) that situational normality influences only perceived ease-of-use, it does not have any influence on perceived usefulness, customer's satisfaction and especially customer's continuance intention. The differences in the results may come from the research context, leading to the fact that the results are inconsistent with one another. The indicators of subjective norm are quite comparative.

Another important factor the author wanted to determine to what extend payment security affects customer's trust in E-wallet. The data analysis outcomes show that payment security is an essential component of customer's continuance intention; an increase in perceive security will raise the customers' trust and induce them to continue using the E-wallet in the future (Kumar, 2018). Therefore, in the Vietnamese context, payment security has a considerable influence upon HCMC residents' trust in using E-wallet application. The results reveal that the safety of customers' bank accounts could be secured sufficiently by E-wallet system $($ mean $=3.289)$. Feedback mechanism is the last factor, which the author attempts to present to the E-wallet service providers.

In this research, it is proven to be an influential factor in customer's trust of E-wallet customers. The research results strongly support previous studies by Shao (2019); more reliable feedbacks from other customers about E-wallet service quality will develop customer's trust and retain existing customers to continue using E-wallet more regularly. The findings indicate that customers believe that information about the service quality provided through the feedback mechanism of E-wallet system is accurate (mean = 3.482). There is increasing evidence of the mobile payment acceptance in Vietnam. Consequently, this research focuses on determining the relative abilities of the constructs to predict continuance intention across HCMC residents. In short, this research integrates TAM, UTAUT and TAM2 theoretical models to investigate determinants affecting customer continuance intention of an E-wallet platform. To sum up the research findings, the authors conclude that mobile quality application and familiarity influence positively perceived ease-of-use (PEOU) and perceived usefulness (PU), but situational normality has an impact only on PEOU. PEOU and PU affect positively customer satisfaction. As the result, customer satisfaction and trust affect considerably customers' continuance intention.

\section{Conclusions and Research Limitations}

This study has several practical implications for E-wallet providers. Based on our findings, the providers should focus on building the trust of their customers and gaining their satisfaction. Firstly, to gain the trust, the platform needs to have the abilities to guarantee its security for customers' bank accounts or their transactions/payments. Secondly, to derive more satisfaction from customers, E- wallet providers should develop high-quality mobile applications with functions that users experienced previously. The mobile application should be attractive, well organized and friendly to customers for conducting payments. The providers must understand their customers properly such as their demographics an habit of mobile phone usage, and get customers' feedback to upgrade the system based on their requirements. Customers will not have difficulties in using E-wallet payment system if the operation processes, layouts and required personal information in the E-wallet platform is similar to other E-wallet platforms.

This research has several limitations. First, it examined variables suggested by the TAM, TAM 2 and UTAUT models and other additional factors. Thus, additional predictors, such as structural assurance, service quality (Ofori, 2017), selfefficacy (Susanto, 2016), performance expectancy (Zhou, 2014) and other social influences could affect customer continuance intention. Secondly, customers sometimes use E-wallet system to make payment due to discounts on bill, cashback payment and free gifts. Therefore, perceived benefit should be investigated further to find out how important these influence customers' E-wallet system continuance intentions. Lastly, future research could investigate the relationship between situational normality and user's trust in the context of E-wallet usage. The positive relationship was already documented in the context of Internet banking (Ofori, 2017).

\section{References}

Abdinoor, A., \& Mbamba, U. (2017). Factors influencing consumers' adoption of mobile financial services in Tanzania. Cogent Business \& Management, 4(1), 1-19. https://doi.org/10 $.1080 / 23311975.2017 .1392273$

Arora, S., \& Sandhu, S. (2018). Usage based upon reasons: The case of electronic banking services in India. International Journal of Bank Marketing, 36(4), 680-700. https://doi.org/10.1007/978981 10-6056-4

Benbasat, I. I., \& Barki, H. (2007). Quo vadis TAM? Journal of the Association for Information Systems, 8(4), 212-218. https://doi. org/10.17705/1jais.00126

Brown, S. A, Venkatesh, V., \& Goyal, S. (2014). Expectation confirmation in information systems research: A test of six competing models. MIS Quarterly, 38(3), 729-756. https://doi. org/10.1287/isre. 1110.0357 
Chawla, D., \& Joshi, H. (2019). Consumer attitude and intention to adopt mobile wallet in India - An empirical study. International Journal of Bank Marketing, 37(3), 1590-1618. https://doi. org/10.1108/ijbm-09-2018-0256

Chen, Y. Y., Huang, H. L., \& Hsu, Y. C. (2010). Confirmation of expectations and satisfaction with the internet shopping: The role of internet self-efficacy. Computers and Information Science, 3(3), 14-22. https://doi.org/10.1109/icgec.2010.171

Cox, C. (2013). The mobile wallet: It's not just about payments. Chicago, IL: Illinois Bankers Association.

Davis, F. D., Bagozzi, R., \& Warshaw, P. R. (1989). User acceptance of computer technology: A comparison of two theoretical models. Management Science, 35(8), 982-1003. https://doi. org/10.1287/mnsc.35.8.982

Doney, P. M., \& Cannon, J. P. (1997). An examination of the nature of trust in the buyer-seller relationship. Journal of Marketing, 61(2), 35-51. https://doi.org/10.1177/002224299706100203

Fathema, N., Shannon, D., \& Ross, M. (2015). Expanding the technology acceptance model (TAM) to examine faculty use of learning management systems (LMSs) in higher education institutions. Journal of Online Learning and Teaching, 11(2), 210-232.

Fornell, C., \& Larcker, D. F. (1981). Evaluating structural equation models with unobservable variables and measurements error. Journal of Marketing Research, 18(1), 39-50. https://doi. org/10.2307/3150980

Gefen, D., Karahanna, E., \& Straub, D. W. (2003). Trust and TAM in online shopping: An integrated model. MIS Quarterly, 27(1), 51-90. https://doi.org/10.2307/30036519

Hair Jr., J. F., Black, W. C., Babin, J. B., \& Anderson, R. E. (1998). Multivariate data analysis with readings (5th ed). Englewood Cliffs, NJ: Prentice-Hall.

Hair, J. F., Hult, G. M., Ringle, C. M., \& Sarstedt, M. (2014). A primer on partial least squares structural equation modeling (PLS-SEM). Thousand Oaks, CA: Sage Publications.

Hajli, N. (2014). A study of the impact of social media on consumers. International Journal of Market Research, 56(3), 387-404. https://doi.org/10.1215/21562261-2801831

Halilovic, S., \& Cicic, M. (2011). Antecedents of information systems user behavior - extended expectation-confirmation model. Behavior \& Information Technology, 32(4), 1-12. https://doi.org/10.1080/0144929X.2011.554575

Han, B., \& Windsor, J. (2011). User's willingness to pay on social network sites. Journal of Computer Information Systems, 51(4), 31-40. https://doi.org/10.1080/0144929x.2011.554575

Hong, I. B., \& Cha, H. S. (2013). The mediating role of consumer trust in an online merchant in predicting purchase intention. International Journal of Information Management, 33(6), 927-939. https://doi.org/10.1016/j.ijinfomgt.2013.08.007

Kim, D., Ferrin, D., \& Rao, R. (2008). A trust-based consumer decision-making model in electronic commerce: The role of trust, perceived risk, and their antecedents. Decision
Support Systems, 44(2), 544-564. https://doi.org/10.1016/j. dss.2007.07.001

Kim, J., Jin, B., \& Swinney, J.L. (2009). The role of retail quality, e-satisfaction and e-trust in online loyalty development process. Journal of Retailing and Consumer Services, 16(4), 239-247. https://doi.org/10.1016/j.jretconser.2008.11.019

Koo, C., Wati, Y., Park, K., \& Lim, M. K. (2011). Website quality, expectation, confirmation, and end user satisfaction: The knowledge-intensive website of the Korean National Cancer Information Center. Journal of Medical Internet Research, 13(4), 81-101. https://doi.org/10.2196/jmir.1574

Kumar, A., Adlakaha, A., \& Mukherjee, K. (2018). The effect of payment security and grievance redressal on continuance intention to use $\mathrm{M}$-wallets in a developing country. International Journal of Bank Marketing, 36(7), 1170-1189. https://doi. org/10.1108/ijbm-04-2017-0077

Le, H. B. H., Ngo, C. T., Trinh, T. T. H., \& Nguyen, T. T. P. (2020). Factor affecting customers' decision to use mobile banking service: A case of Thanh Hoa Province, Vietnam. Journal of Asian Finance, Economics, and Business, 7(2), 205-212. https://doi.org/10.13106/jafeb.2020.vo17.no2.205

Lee, C. Y., Tsao, C. H., \& Chang, W. C. (2015). The relationship between attitude toward using and customer satisfaction with mobile application services: An empirical study from the life insurance industry. Journal of Enterprise Information Management, 28(5), 680-697. https://doi.org/10.1108/JEIM07-2014-0077

Lee, J. W., Becker, K., \& Potluri, R. M. (2016). Antecedents of corporate adoption of social media and the role of the technology acceptance model in the path. Journal of Asian Finance, Economics and Business, 3(2), 67-76. https://doi. org/10.13106/jafeb.2016.vol3.no2.67

Lee, W.-J. (2019). Evaluating perceived smartness of product from consumer's point of view: The concept and measurement. Journal of Asian Finance, Economics and Business, 6(1), 149-158. https://doi.org/10.13106/jafeb.2019.vol6.no1.149

Magsamen-Conrad, K., Upadhyaya, S., Joa, C.Y., \& Dowd, J. (2015). Bridging the divide: Using UTAUT to predict multigenerational tablet adoption practices. Computers in Human Behavior, 50, 186-196. https://doi.org/10.1016/j. chb.2015.03.032

Martins, C., Oliveira, T., \& Popovič, A. (2014). Understanding the internet banking adoption: a unified theory of acceptance and use of technology and perceived risk application. International Journal of Information Management, 34(1), 1-13. https://doi. org/10.1016/j.ijinfomgt.2013.06.002

Nguyen, N. D. P., \& Nguyen, T. D. (2018). The effect of countryof-origin on customer purchase intention: A study of functional products in Vietnam. Journal of Asian Finance, Economics and Business, 4(3), 75-83. http://dx.doi.org/10.13106/jafeb.2017. vol4.no3.75

Ofori, K. S., Boateng, H., Okoe, A. F. \& Gvozdanovic, I. (2017). Examining customers' continuance intentions towards internet 
banking usage. Marketing Intelligence \& Planning, 35(6), 756-773. https://doi.org/10.1108/mip-11-2016-0214

Pavlou, P. A., \& Gefen, D. (2004). Building effective online marketplaces with institution-based trust. Information Systems Research, 15(1), 37-59. https://doi.org/10.1287/isre.1040.0015

Sachan, A., Kumar, R., \& Kumar, R. (2018). Examining the impact of e-government service process on user satisfaction. Journal of Global Operations and Strategic Sourcing, 11(3), 321-336. https://doi.org/10.1108/jgoss-11-2017-0048

Salem, M. Z., Baidoun, S., \& Walsh, G. (2019). Factors affecting Palestinian customers' use of online banking services. International Journal of Bank Marketing, 37(2), 426-451. https://doi.org/10.1108/IJBM-08-2018-0210

Shang, W. W. D. (2017). Understanding mobile shopping consumers' continuance intention. Industrial Management \& Data Systems, 117(1), 213-227. https://doi.org/10.1108/ijbm08-2018-0210

Shao, Z., \& Yin, H. (2019). Building customers' trust in the ridesharing platform with institutional mechanisms: An empirical study in China. Internet Research, 29(5), 1040-1063. https://doi.org/10.1108/INTR-02-2018-0086

Shaw, N. (2014). The mediating influence of trust in the adoption of mobile wallet. Journal of Retailing and Consumer Services, 21(4), 449-459. https://doi.org/10.1016/j. jretconser.2014.03.008

Shin, D. H. (2009). Towards an understanding of the consumer acceptance of mobile wallet. Computers in Human Behavior, 25, 1343-1354. https://doi.org/10.1504/ijmc.2016.075022

Susanto, A., Chang, Y., \& Ha, Y. (2016). Determinants of continuance intention to use the smartphone banking services. Industrial Management \& Data Systems, 116(3), 508-525. https://doi.org/10.1108/imds-05-2015-0195

Tabachnick, B. G., \& Fidell, L. S. (1996). Using multivariate statistics. New York, NY: Harper Collins.

Venkatesh, V., \& Bala, H. (2008). Technology acceptance model 3 and a research agenda on interventions. Decision Sciences, 29(2), 273-315. https://doi.org/10.1111/j.15405915.2008.00192.x
Venkatesh, V., Morris, M. G., Davis, G. B., \& Davis. D. F. (2003). User acceptance of information technology: Toward a unified view. MIS Quarterly, 27(3), 425-478. https://doi. org/10.2307/30036540

Wu, C. G., \& Wu, P. Y. (2018). Investigating user continuance intention toward library self-service technology: The case of self-issue and return systems in the public context. Library Hi-Tech, 37(3), 401-417. https://doi.org/10.1108/lht-02-20180025

Yang, S. B., Lee, K., Lee, H., Chung, N., \& Koo, C. (2016). Trust breakthrough in the sharing economy: An empirical study of Airbnb. In: The 20th Pacific Asia Conference on Information Systems. PACIS 2016 Proceedings. https://aisel.aisnet.org/ pacis2016/131

Yeh, Y. H., \& Li, Y. M. (2009). Building trust in m-commerce: Contributions from quality and satisfaction. Online Information Review, 33(6), 1066-1086. https://doi. org/10.1108/14684520911011016

Cao, X., Yu, L., Liu, Z., Gong, M., \& Adeel, L. (2018). Understanding mobile payment users' continuance intention: A trust transfer perspective. Internet Research, 28(2), 456-476. https://doi.org/10.1108/intr-11-2016-0359

Zhang, H., Lu, Y., Gupta, S., \& Gao, P. (2015). Understanding group-buying websites continuance - an extension of expectation confirmation model. Internet Research, 25(5), 767-793. https://doi.org/10.1108/intr-05-2014-0127

Zhou, T. (2011). An empirical examination of initial trust in mobile banking. Internet Research, 21(5), 527-540. https://doi. org/10.1108/10662241111176353

Zhou, T. (2014). Understanding the determinants of mobile payment continuance usage. Industrial Management \& Data Systems, 114(6), 936-948. https://doi.org/10.1108/imds-022014-0068

Zhou, W., Tsiga, Z., Li, B., Zheng, S., \& Jiang, S. (2018). What influence users' e-finance continuance intention? The moderating role of trust. Industrial Management \& Data Systems, 118(8), 1647-1670. https://doi.org/10.1108/imds-122017-0602 